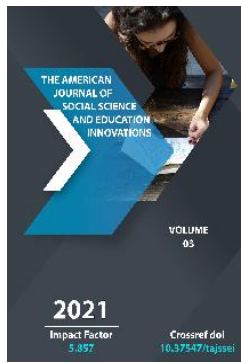

\title{
The Importance Of Quality Issues In The Teaching Of Physics
}

\author{
Yuldashev Laziz Tashpulatovich \\ Lecturer, Almalyk Branch Of Tashkent State Technical University Named After Islam Karimov, The \\ Republic Of Uzbekistan, Almalyk, Uzbekistan
}

\begin{abstract}
Journal Website:
http://theamericanjour

nals.com/index.php/taj

ssei

Copyright: Original content from this work may be used under the terms of the creative commons attributes 4.0 licence.
\end{abstract}

\section{ABSTRACT}

This article discusses one of the methods of organizing education, the possibilities and methods of using quality issues in achieving pedagogical goals in physics lessons.

\section{KEYWORDS}

Issue, laws, quantitative, graphical, qualitative issues, observations, method.

\section{INTRODUCTION}

In the era of renewal of all strata of society, the system of preschool, secondary, special vocational and higher education is entering a new stage of development.
The following statements by the President are vivid proof of this: "Increasing competition in the context of globalization requires the development and implementation of a completely new approach and principles for a 
more stable and dynamic development of our country" [1].

Solving problems in physics is an integral part of the educational process and one of the main practical methods. The selected topics should relate to natural phenomena, the life experience of students, the national economy, industry, production in their place of residence.

\section{LITERATURE REVIEW}

In this article, on the methodology for solving problems in physics, an analysis of the literature related to this field was carried out. V.A. Balashov manual on solving the problems of a course in elementary particle physics, designed for independent students studying physics, preparing for admission to higher educational institutions, students of physics and mathematics faculties of pedagogical institutes and high school students [1]. The author developed unified methods for solving problems from the course of elementary particle physics, tried to show the use of these methods in solving specific problems. But this manual does not pay much attention to quality issues, logical thinking.

V.M. Spiransky's manual presents a system of methods for solving problems in the main sections of the course of elementary particle physics and analyzes characteristic errors that arise in solving problems [2]. The author tries to teach his readers to solve physical problems. Without specifying how to solve the problem, several simple solutions to the problem are given. This manual is intended for use by students of pedagogical higher educational institutions, students and teachers of general education schools. But in this manual, there are no conclusions revealing processes in the natural-technical sphere adapted for university students.

The educational and methodological manual, co-authored with M. Nassov, O. Bozorov, S. Yulchiev, presents a general classification of physics issues, as well as problems of various complexity and methods for solving them, recommended in subsequent years at regional, regional and republican Olympiads in physics [3]. In addition, it would be useful if the guide focused on quality issues.

Even though in the teaching manual coauthored by A.L. Surkaev, M.M. Kumysh, M.M. Rakhmankulova, the general sequence of physics issues is presented in the usual order, we see that it pays little attention to quality issues. It is desirable that the answers to the questions raised for self-work be given at the end of the question [4].

Ishmurodova G.I. and Maxmanov E.B. The article "Formation of students' skills in solving logical problems in physics", co-authored, notes that the development of logical teaching in Central Asia had a direct impact on the formation of the worldview of Farobi, Ibn Sina, Ibn Rushd, Beruni and other progressive thinkers. Also, in recent years, the importance of their use in physics lessons has been highlighted, given the lack of use of logical issues in the formation of scientific worldviews of students, the development of quick thinking, intellectual and intellectual abilities [5-12].

\section{MATERIALS AND METHODS}

Problems in a creative context - problems that are solved by an algorithm - are unknown. The conditions of such problems are abstract, the 
given ones are lacking, or there are unnecessary excesses, and sometimes data from the field needed to solve the problem is not given. Solving any problem consists of three steps: reading, analyzing, and solving its condition. Analyzing the content of a problem is the most responsible step, and solving it starts with reading it carefully several times and understanding its content. As soon as you read the condition of the problem to be solved, you should not immediately focus on the amount you are looking for, do not try to find it quickly. On the contrary, it is necessary to have a good understanding of the physical phenomena reflected in the subject, to fully imagine this natural process, and to remember the physical laws and formulas to be applied. If it is necessary to find an unknown, to prove that a sequence of events obeys a fundamental law, it is necessary to determine what values are given in the problem, as well as the hidden conditions, the quantities to be found. It is necessary to answer the question of why, that is, it is explained to students based on known laws, as well as by drawing graphs, drawings and pictures. Quantitative, graphical, qualitative and other issues are solved in classes and extracurricular activities.

Quality issues activate students. Arithmetic calculations are not performed when solving this type of problem. Based on physical laws, rules, definitions, equations and formulas, the solution to the problem is given in the form of a set of logical thinking sequences. Qualitative issues clearly explain to students physical phenomena and their laws, teach them to apply theoretical knowledge in practice. Especially students who have just started to work on the problem develop curiosity, understanding of natural processes, the ability to manage processes in accordance with the principles of simple to complex, easy to difficult. Pedagogical observations confirm this fact. Therefore, below are examples of solving quality problems related to these requirements, related to common events and processes in everyday life, industry, various areas of production, as well as in practical training to strengthen the topic, deepen logical conclusions.

1. Does the hydraulic machine work in zero gravity?

Solution: The hydraulic machine works in zero gravity conditions. The transfer of pressure is based on the opposing forces (elastic force) that arise between the liquid molecules as a result of their convergence. These forces (Ffric $=-k x)$ do not depend on the weight of the liquid.

2. A bottle filled with water and closed with a stopper is immersed in water. Does a bottle with the same filling of mercury sink in mercury or float?

Solution: Since the total density (r) of the water bottle is greater than the density of water (rs), it will sink in the water. Since the total density of a mercury vessel (rmercury) is less than that of mercury, it floats in the mercury.

3. A piece of ice floats in a full bucket. Will water overflow when the ice melts?

Solution: According to Archimedes' law ( $\mathrm{Fa}=$ pcvжg), a force equal to the weight of water squeezed out of the ice lifts the ice vertically, i.e. the weight of the ice is equal to each other. In this case, their masses are also equal. From this, we can conclude that the volume of 
water formed as a result of melting is equal to a fraction of the volume of ice immersed in water. This means that when the ice melts, the water level does not change, resulting in no flooding.

4. What is the significance in nature of the high specific temperature of melting of snow and ice?

Solution: At the end of autumn, the air does not cool down sharply under the influence of thermal energy released during the formation of snow and ice.

Conversely, in early spring, thermal energy is spent on melting snow and ice, and the air does not immediately heat up. As a result, when the seasons change, the air temperature stabilizes to a certain extent. The significance of this for human activity, flora and fauna are well known.

5. The cooking time of the meat does not depend on whether the soup is cooked on a high or low flame. Why?

Solution: The boiling point of water does not exceed 100 degrees, even with a strong flame. For independent work and extracurricular activities, similar issues can be recommended.

1. A piece of ice floats in a bowl of water.

How does the water level change after the ice melts?

Consider the following:

a) There is an air bubble inside a piece of ice;

b) There is a stone inside the ice block;

c) There is foam inside a piece of ice;
2. There is ice at the bottom of the bucket.

When water is poured over it, the ice melts.

Will the water level rise or fall?

1. Does the pipette draw more liquid at the foot of a mountain or at the top of a mountain?

2. The specific heat capacity of cast iron and steel is greater than that of copper.

Why is the welder made of copper and not iron and steel?

3. Cooking pasta in a saucepan.

Does the water inside the pasta tube boil when the water boils?

4. The cloud leaves a trail behind a high flying plane.

Explain the reason.

5. People living in the mountains, when cooking meat, tightly close the lid of the pan and put a stone on it.

Why is this done?

\section{RESULTS}

Experience shows that solving quality problems strengthens students' theoretical knowledge of physics, allows them to master a given topic in-depth and detail. It will lead to the formation of initial skills and competencies in future professionals, as well as the growth of creative abilities and professional competence. Students' logical thinking is activated. The ability to conduct scientific research on their economies is formed, the 
resulting creative ability leads to the development of the ability to work independently. Skills and competencies in working with additional technical literature are formed, specific skills and competencies for daily life and work process are formed. In addition, speciality-oriented practical training plays an important role in the development of integration of education and production. Conducting practical classes will further improve the quality of the educational process, increase students' interest in physics and develop observation.

\section{REFERENCES}

1. Mirzieyov Sh.M. (2017). On the strategy of further development of the Republic of Uzbekistan. Voice of Uzbekistan.

2. Balash, V.A. (1964). Physics problems and methods for their solution. Education.

3. Speransky, N.M. (1967). How to solve problems in physics. High school.

4. M.Nosirov, O.Bozorov, Sh.Yulchiev. Olympic problems in physics.

5. Surkaev, A.L., Rakhmankulova, G.A., Sukhova, T.A., \& Kumysh, M.M. (2019). A guide to solving problems. Physics.

6. Perelman, J. (2020). Do you know physics ?. Liters.

7. Perelman, J. (2018). Entertaining tasks and experiences. Liters.

8. Tulchinsky M.E. (1972). High-quality physics problems in high school. A guide for teachers. M.: Education.

9. Bazarova, S. D., \& Baychaev, F. X. (2020). Specialized practical training is a factor for developing education and production integration. Journal of
Advances in Engineering Technology, (1).

10. Samadov, A., Nosirov, N., Qosimova, M., Muzafarova, N., \& Almalyk, B. (2021). Processing of layout tails of gold-extracting factories. Збірник наукових праць SCIENTIA.

11. Nosirov, N. (2021). Taking samples of straight tails of the tails of the gold extraction factory. Збірник наукових праць SCIENTIA.

12. Zikirov, M. C., Qosimova, S. F., \& Qosimov, L. M. (2021). Direction of modern design activities. Asian Journal of Multidimensional Research (AJMR), 10(2), 11-18. 